\title{
Garcilaso y las teorías del Tipo Ideal y de la Estructura
}

\author{
POR LUIS E. VALCÁRCEL
}

Entre las significativas anticipaciones del Inca historiador, cabe resaltar su concepción tan moderna de tratar la materia histórica como si hubiese adivinado las teorías del Tipo Ideal y de la Estructura.

Debemos a Max Weber la definición del primero como "una figura mental unitaria, rəsultante de la captación de un conjunto de hechos ligados estrechamente entre sí, o de un sistema de ideas abstractas". Agrega Weber que esta figura mental unitaria cobra vida y actúa como arquetipo. Distingue entre el producto puramente ideológico -querdesemboca en lutopíaterdel fruto de observaciones realistas que se convierte en el objetivo de una praxis. Cuando se ha plasmado el T.ipo Ideal, el político, el grupo director, trata de canalizar, de acomodar la vida del pueblo, al modelo escogido, llevando adelante la transformación social y el mejoramiento humano por los medios que se consideran más eficaces. Sin embargo, el Tipo Ideal persigue su realización por métodos lógicos, ya sea en forma empírica, ya de arreglo a planeación. Puede también distinguirse entre procedimientos de lentitud evolucionista o de aceleración revolucionaria.

El proceso está sometido a un severo control que trata de impedir todo acto que se aparte o contradiga al Tipo Ideal. Es la historia la que se encarga de revelarnos en qué medida de aproximación se ha cumplido la tarea, cuáles fueron los éxitos y cuáles las desviaciones.

Freyer coincide con las ideas de Weber cuando escribe este párrafo: "La vida de los hombres fluye durante un período histó- 
rico en la forma de un orden social o de un sisterna político. La vida no prosigue su curso en forma múltiple y ablgarrada, sino que se sitúa a sí misma en un cauce y bajo una forma. No se ha creado una obra con un sentido intemporal, sino que la realidad social misma se condensa, convirtiéndose en existencia conformada".

Todo tipo ideal es, al mismo tiempo, una estructura históri. ca. La historia precisamente nos revela en qué medida el tipo ideal conforma la estructura y de qué manera ésta funciona para realizar el arquetipo. Se ha definido la estructura como un sistema de relaciones, dentro del cual cada hecho adquiere un sentído en función de todos los otros, con los que se halla en conexión. De ahí que todo hecho debe ser examinado por la historia. conectado con la respectiva estructura, porque la realidad histórica -se añade- está configurada, no en los hechos aislados, sino en las estructuras. La misión del historiador consiste en descubrirlas.

Dilthey había definido la estructura como "un orden con arreglo al cual los hechos psíquicos se hallan enlazados entre sí. mediante una relación interna". Huizinga, por su parte, había hecho notar que "toda obra de historia construye conexlones, esboza formas, a través de las cuales nos hace comprender la realidad pasada".

Una particularidad de la conexión histórica es la de que los hechos de una estructura se relacionan en circulo y no en cadena.

El Inca Garcilaso -y éste es su gran mérito-- había descubierto el Tipo Ideal y la Estructura del Imperio Incaico, al poner el mayor énfasis en aquellos órdenes de actividad cultural básicos, como son la Economía y la Política. Recuérdese que estas materias las trata en 75 capítulos, amén de las referencias sueltas que aparecen en diferentes partes de la obra. El ordon que le sigue es de la Religión en 38 capítulos, en los cuales se percibe su trasfondo político-económico.

Al concebir nítidamente el Tipo Ideal perseguido por los Reyes Incas, Garcilaso, con un optimismo que algunos consideran exagerado, comprueba cómo a lo largo de la historía del Imperio se va cumpliendo, sin apartarse apenas del arquetipo, puesto que las instituciones funcionaban adecuadamente.

El sistema de tenencia de la tierra y de los demás bienes, el del trabajo, el de la previsión social, la organización administrati- 
va, forman una sólida estructura llamada a funcionar sin tropiezos. El tipo ideal de sociedad imaginado por los Incas y llevado a la práctica, tenía por objetivo supremo extender el bienestar al íntegro de la población. ¿Fueron o no satisfechas plenamente las necesidades primordiales del hombre?. Ningún historiador se atreve a negarlo. Todos los testimonios concuerdan en que el objetivo fue alcanzado. Los "Comentarios Reales" se circunscriben a esa comprobación. Que, en todo lo demás, (acontecimientos, creencias religiosas) hubiera fallas, disconformidad con otros cronistas, es cosa de menor importancia. La autoridad de Garcilaso es insuperable en lo esencial : en el sistema político-económico que implantaron los Incas. Nadie como él concibió el Tipo Ideal y la Estructura, el cuadro completo de la sociedad inca, la visión cabal de su cultura, destacando precisamente aquello en que el Perú ofrece una permanente enseñanza, y precisamente también en lo que estriba su auténtica originalidad.
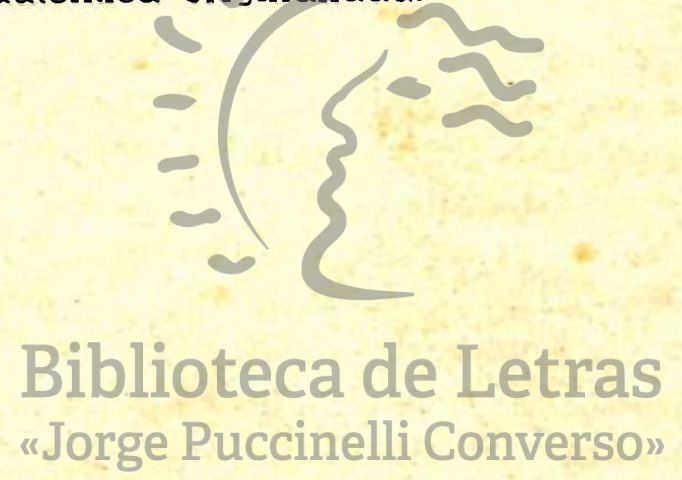